\title{
Vertebral Destruction Syndrome: From Knowledge to Practice
}

Jose Maria Jimenez-Avila ${ }^{1,2}$, Mario Alberto Cahueque-Lemus ${ }^{3}$, Andres Enrique Cobar-Bustamante ${ }^{3}$ and Maria Cristina Bregni-Duraés ${ }^{4}$

${ }^{1}$ Spine Surgeon, Western Medical Center Hospital, Guadalajara, Jalisco, Mexico

${ }^{2}$ Faculty of Medicine professor, Mexican Institute of Social Security, TEC de Monterrey, Guadalajara, Jalisco, Mexico

${ }^{3}$ Orthopedic Surgeon, Western Medical Center Hospital, Guadalajara, Jalisco, Mexico

${ }^{4}$ Orthopedic Surgeon, Guatemalan Social Security Institute, Guatemala, Guatemala, Mexico

\begin{abstract}
The term Vertebral Destruction Syndrome comprises pathologies causing structural changes in the spine in the vertebral body mainly producing mechanical deformity and neurological involvement. Among the pathologies found in this definition are infectious and metabolic tumors. The vertebral osteomyelitis is a disease that occurs mainly in adults $>50$ years; we speak of spondylodiscitis when condition affects the disc and vertebral body. The most important in the vertebral body is Staphylococcus aureus osteomyelitis, seen in over $50 \%$ of cases. Tumors of the spine can start from local or adjacent spinal injuries or distant spread through the blood or lymphatic. Metastases injuries account for about $97 \%$ of all tumors of the spine. Primary tumors that most commonly spread to spine is lung, prostate, breast and kidney. Metabolic bone diseases are a group of disorders that occur as a result of changes in calcium metabolism, spine contains large amounts of metabolically active cancellous bone, which must withstand axial loads during stance, and osteoporosis is a metabolic disease that most commonly affects the spine, characterized by low bone mass.
\end{abstract}

The diagnosis of these entities is important for treatment and prognosis of the patient, the term Vertebral Destruction Syndrome proposes a notarized scheme aimed at improving patient prognosis and their prompt treatment.

Keywords: Vertebral destruction syndrome; Spondilydiscitis; Spinal tumors; Osteomyelitis

\section{Introduction}

The term Vertebral Destruction Syndrome comprises a group of different pathologies that cause structural change in the spine, mainly in the vertebral body and resulting in mechanical and neurological consequences. Among these, are Neoplastic, Metabolic and Infectious cause's vertebral destruction syndrome (Figure 1).

\section{Infectious etiology}

Vertebral Osteomyelitis is an estimated $5 \%$ of all bone infections. The vertebral body can be affected without the intervertebral disc being involved, due to hematogenous Spread of the disease. The most important infecting organism is Staphylococcus aureus, which is responsible for more than $50 \%$ of cases in developing countries, followed by Mycobacterium Tuberculosis rods. Other bacteria responsible for this disease are Brucella melitensis, Pseudomona aeureginosa and Candida spp.

Spondilydiscitis is recently known to be a rising type of spinal infection in the last 15 years, due to invasive diagnostic and treatment procedures that result in bacteremia and sepsis.

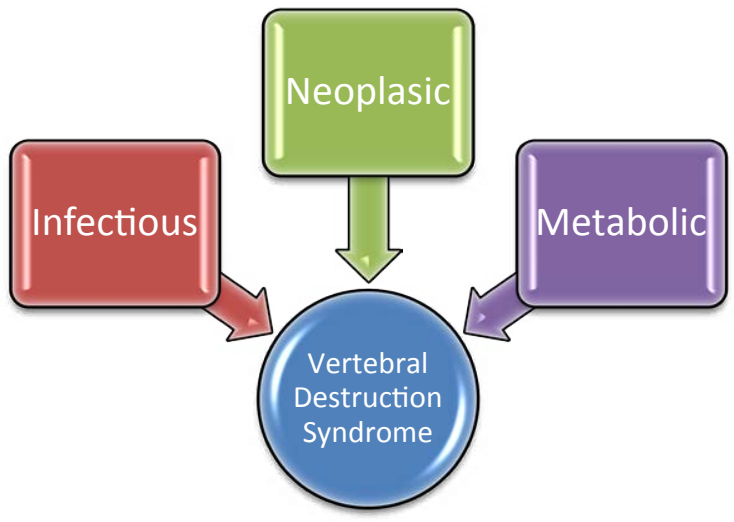

Figure 1: Neoplasic, metabolic and infectious causes vertebral destruction syndrome.

\section{Neoplastic etiology}

Spinal tumors can both be local or distant, arising from the hematogenous or lymphatic Spread of malignant cells. Metastatic tumors comprise $97 \%$ of all neoplastic pathology of the spine, and among the most common sites of origin are the lung, prostate gland, mammary gland and kidney [1-3].

Metastatic tumors are the most frequent type of vertebral tumors, its presentation consisting in pain in $85 \%$ of patients and other types of radicular symptoms in another $20 \%$. Pain is characteristically of slow progression and is not related to physical activity, but is mainly of nocturnal presentation. The pain can be reproduced by causing pressure on the affected area, and the patient can report parentheses and other radicular symptoms, based on the affected spinal level $[4,5]$.

Vertebral destruction in osteomyelitis can be similar radiographically, but the height of the vertebrae is reduced in infectious diseases, whereas in neoplastic diseases this is preserved. The differential diagnosis is important in decision making of definitive diagnosis and treatment (Table 1).

The main role of the biopsy procedure and sample is the confirmation of metastatic disease, and it is important to also rule out infectious pathology. The objective of the treatment in patients with spinal tumors is to not only to find a cure for the disease, but also provide relief of symptoms and rehabilitation of disabilities by providing stability of the spine and improving neurological function [6].

*Corresponding author: Jose Maria Jimenez Avila, Spine Surgeon, Western Medical Center Hospital, Faculty of Medicine Professor, Mexican Institute of Social Security, TEC de Monterrey, Guadalajara, Jalisco, Mexico, Tel: 3310704802; E-mail: josemajimeneza@hotmail.com

Received July 08, 2015; Accepted August 11, 2015; Published August 13, 2015

Citation: Jimenez-Avila JM, Cahueque-Lemus MA, Cobar-Bustamante AE Bregni-Duraés MC (2015) Vertebral Destruction Syndrome: From Knowledge to Practice. J Spine 4: 251.doi:10.4172/2165-7939.1000251

Copyright: (c) 2015 Jimenez-Avila JM, et al. This is an open-access article distributed under the terms of the Creative Commons Attribution License, which permits unrestricted use, distribution, and reproduction in any medium, provided the original author and source are credited. 


\begin{tabular}{|l|l|l|}
\hline Differential Diagnosis of vertebral body injuries \\
\hline Multiple & Isolated & Tumor-like \\
\hline Hemangiomas & Chordoma & Degenerative disease \\
\hline Metastatic disease & Giant-Cell Tumor & Infection \\
\hline Multiple Myeloma & Aneurysmatic Cyst & Metabolic disease \\
\hline Linphoma & Osteoid Osteoma & Dysplasia \\
\hline Leukemia & Osteoblastoma & Avascular Necrosis \\
\hline Langerhans Cell Hystiositosis & Plasmocytoma & \\
\hline & Osteosarcoma & \\
\hline & Ewings Sarcoma & \\
\hline & Neuroblastic Tumors & \\
\hline
\end{tabular}

Table 1: Differential diagnosis of injuries of the vertebral spine.

\section{Metabolic etiology}

Osteoporosis is he most frequently encountered metabolic disease, and can result in compression fractures that cause pain in the lower area of the spine, as well as kyphotic deformity. Osteomalacia is a less common disease, but can present itself in a similar manner. Paget's Disease is an excessive bone formation which occurs in an expansive pattern resulting in compression of the dural sac and its elements. Among the metabolic causes of spinal disease, Osteoporosis is the most common, with up to a quarter of women over 65 years of age being involved. It is responsible for 1.5 million fractures in the United States each year of which 500,000 correspond to vertebral fractures; however, this is a silent disease with most of the fractures being asymptomatic [7].

\section{Vertebral Destruction Syndrome}

The Vertebral Destruction Syndrome is a disease of multiple etiologies, characterized by alterations in the anatomy of the spine, specifically deformity and size increment of the vertebral bodies adjacent to the injury, which is related to neurological and mechanical disabilities. The causes associated to the disease are infectious (bacterial and fungal), metabolic (osteoporosis) and neoplastic, (primary and metastatic) and the proposed diagnosis must be made under the correct analysis of the disease in mention [8].

\section{"The imaging study does not result in diagnosis"}

The initial approach to the patient in the emergency room begins in screening, and must be made by a cautious and detailed history, consisting in the presence of pain and its localization, history of fever, night sweats, weight loss, and certain specific details, such as consumption of non-pasteurized milk products that alerts us of potential infection with Brucella Melitensis. The clinical diagnosis can confuse the physician, just as in the case of a patient with the clinical and radiologic characteristics of a spinal Lymphoma, and the actual disease being a vertebral osteomyelitis with Bartonella Henslae infection $[9,10]$ (Figure 2).

Imaging techniques are of importance with the history of the disease, observing loss of intervertebral height seen in bacterial infection, and the vertebral disc not being involved in mycobacterial and fungal disease.

In neoplastic disease, a single vertebral body can be involved, with evidence of collapse and pedicle involvement in the setting of metastatic disease along with sagital balance deformity, scoliosis and laterolisthesis. Anatomical structures and deformity can best be appreciated in Computed Tomographic Scans. In cases of Multiple
Myeloma, magnetic resonance imaging is the method of choice in the approach of the evaluation of the spine, and gammagraphy in the scenario of metastatic injuries.

In the suspicion of neoplastic injuries of the spine, screening methods include specific serological testing. Diagnostic tests such as Bence Jones Protein, Bone Marrow Aspirate, Erythrocyte sedimentation rate and Reactive C Protein are used not only for diagnosis but also for follow up purposes $[10,11]$.

Among the diagnostic methods to assess bone mineral density, Dual Energy X- Ray Absorption (DEXA) is a rapid and useful tool, due to its precise information for the surgeon to assess whether an implant can tolerate the axial load on an implant $[12,13]$.

\section{Treatment}

\section{Infectious etiology}

In the event of the suspicion of Vertebral Osteomyelitis, the bone biopsy and cultivation for microbiological purposes is indicated previous to the administration of antibiotic therapy. Surgery is indicated under the following circumstances [14].

\section{Cultivation for bacteriological diagnosis}

Clinically evident abscess formation (in the presence of fever)

Cases that is refractory to the previously established treatment (persisting fever, elevated Erythrocyte Sedimentation Rate and C reactive protein)

\section{Spinal cord involvement}

Instability secondary to significant deformity or vertebral body involvement

\section{Metabolic etiology}

Osteoporosis: Osteoporosis is the most prevalent type of bone mineral deficiency in adult patients. This disease is responsible for about 1.5 million fractures per year, and in nearly half of these the vertebral bodies are involved. A third of the female population over 65 years old suffers of at least one vertebral fracture. The treatment of these patients is mainly prophylactic, with the administration of pharmacologic therapy [15].

The majority of patients with fractures due to osteoporosis are initially managed in a non-operative manner. Pain medication, rest, ortheses and physical therapy are the mainstray of treatment. Early mobilization of the patient is important, and both vertebroplasty and kyphoplasty reduce symptoms and pain in patients with compression fractures, that do not improve with non-operative treatment $[16,17]$.

\section{Neoplastic etiology}

Tumors that result in vertebral body destruction are 95\% of metastatic origin, and mainly arise from lung, prostate, mammary gland and kidney cancer $[18,19]$.

Chemotherapy has limited use when it comes to metastatic tumors, and most patients are referred to radiotherapy treatment, with up to $80 \%$ of patients treated successfully. The combination of radiotherapy and surgical treatment is the usual method of choice, and instability and neurological impairment are the determining factors for surgical treatment [20].

\section{Conclusions}

Vertebral spine injuries can have a varied clinical and radiologic 


\section{Vertebral Destruction Syndrome (SDV)}

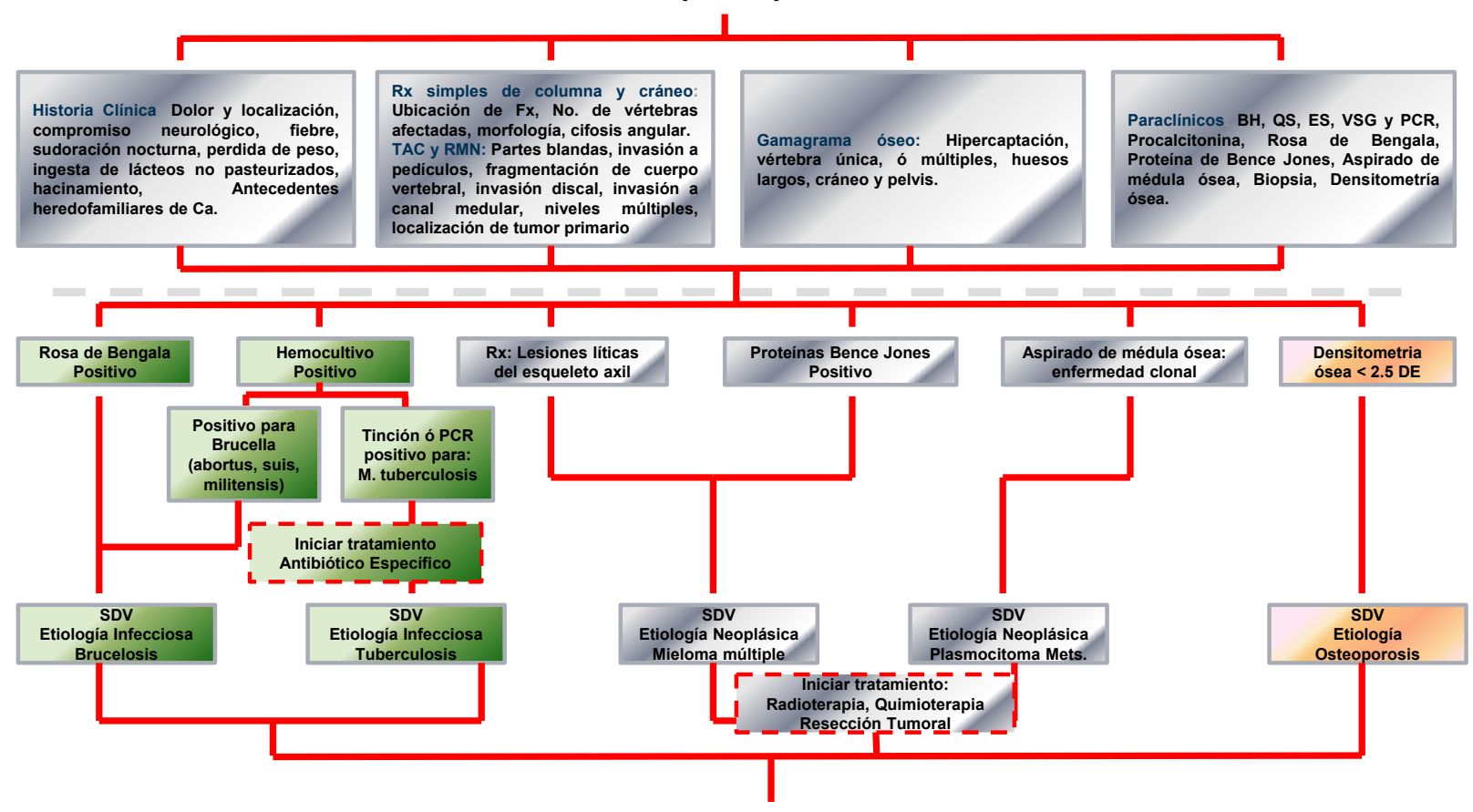

Figure 2: Screening algorithm and diagnosis for vertebral destruction syndrome.

\section{$1^{\circ} \mathrm{S}$}

\section{Vertebral Destruction Syndrome}

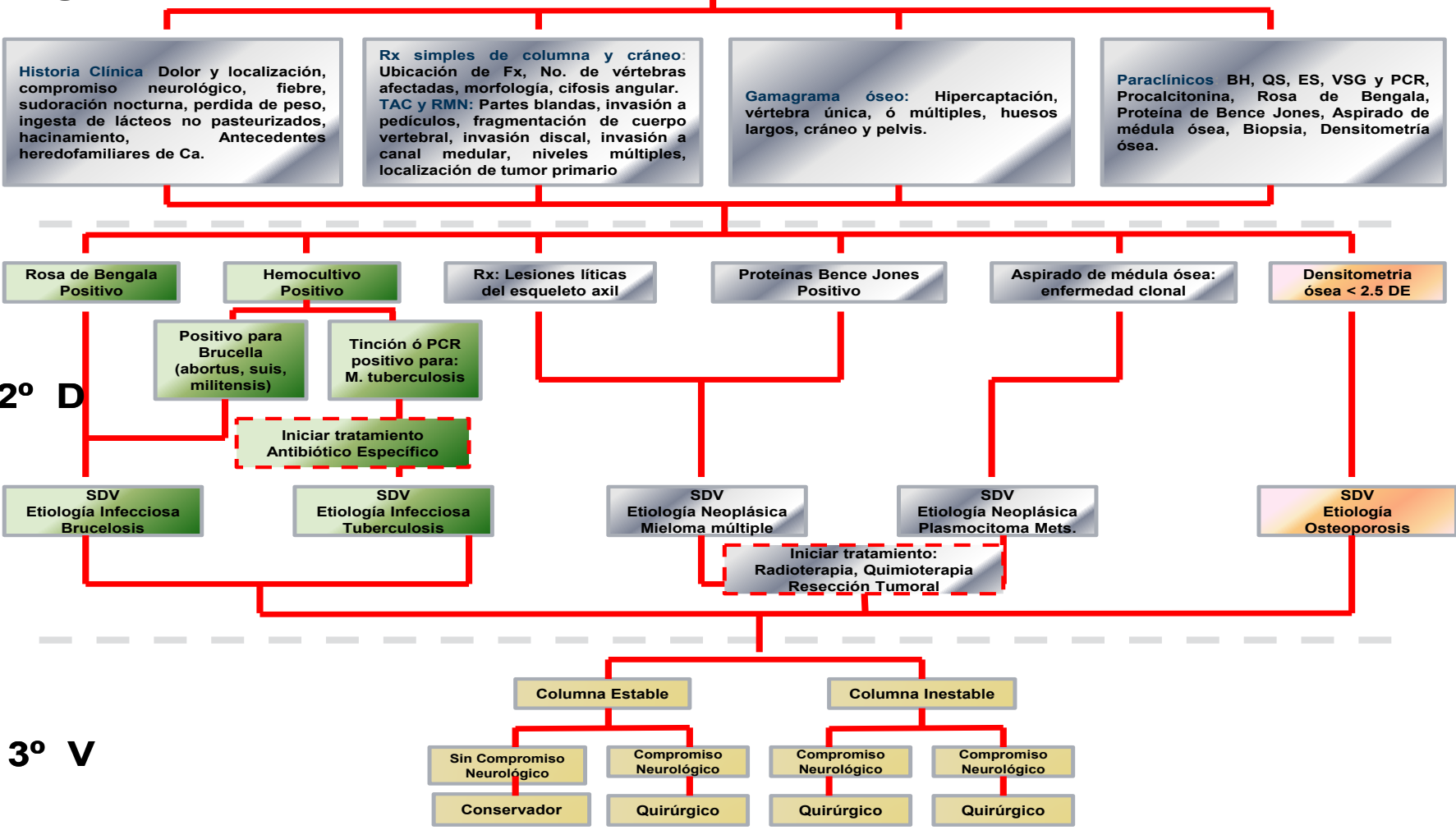

Figure 3: Treatment algorithm vertebral destruction syndrome. 
presentation, being of infectious, neoplastic or metabolic origin, resulting in a confusing diagnosis for the treating physician. The multiple possibilities of causes of this disease result in anatomical alterations of the spine, and are accompanied by pain and functional disability due to mechanical and neurological changes.

The diagnosis of Vertebral Destruction Syndrome comprises a series of diagnostic steps in the assessment of the patient, analyzing each in a systemized and timely fashion, addressing each of the factors that can affect the patient. Each of the etiologies that cause the syndrome to share common characteristics, which are commonly described in medical literature, but it is important to consider the singularities of each of the presenting clinical settings, to permit a systematic approach to each entity, reducing the time to diagnosis and treatment. This systematic approach to the evaluation of the patient that is proposed must take advantage of the diagnostic tools indicated for each of the before mentioned etiologies, in accordance to avoiding false positive results that may not only delay diagnosis, but affect the ideal and prompt treatment of the patient (Figure 3).

\section{References}

1. DeSanto J, Ross JS (2011) Spine infection/inflammation. Radiol Clin North Am 49: 105-127.

2. Mylona E, Samarkos M, Kakalou E, Fanourgiakis P, Skoutelis A (2009) Pyogenic vertebral osteomyelitis a systematic review of clinical characteristics. Semin Arthritis Rheum: 10-17.

3. Mesfin A, Buchowski JM, Gokaslan ZL, Bird JE (2015) Management of Metastatic Cervical Spine Tumors. J Am Acad Orthop Surg 23: 38-46.

4. Mizumoto $\mathrm{M}$, Harada $\mathrm{H}$, Asakura $\mathrm{H}$, Hashimoto $\mathrm{T}$, Furutani $\mathrm{K}$, et al. (2011) Radiotherapy for patients with metastases to the spinal column: a review of 603 patients atShizuoka Cancer Center Hospital. Int J Radiat Oncol Biol Phys 79: 208-213.

5. Switlyk MD, Kongsgaard U, Skjeldal S, Hald JK, Hole KH, et al. (2015) Prognostic Factors in Patients with Symptomatic Spinal Metastases and Normal NeurologicalFunction. Clin Oncol (R Coll Radiol) 27: 213-221.

6. Sehn JK, Gilula LA (2012) Percutaneous needle biopsy in diagnosis and identification of causative organisms in cases of suspected vertebral osteomyelitis. Eur J Radiol 81: 940-946.

7. Zapalowicz K, Radek M (2015) Percutaneous balloon kyphoplasty in the treatment of painful vertebral compression fractures: Effect on local kyphosis and one-year outcomes in pain and disability. Neurol Neurochir Pol 49: 11-15.

8. Alpizar-Aguirre A, Elías-Escobedo A, Rosales-Olivares LM, MiramontesMartínez V, Reyes-Sánchez A (2008)Vertebral destruction syndrome. Diagnostic evaluation systems. Cir Cir 76: 205-211.

9. Turunc T, Demiroglu YZ, Uncu H, Colakoglu S, Arslan HA (2007) Comparative analysis of tuberculous, brucellar and pyogenic spontaneous spondylodiscitis patients. J Infect 55: 158-163.

10. Dunbar JA, Sandoe JA, Rao AS, Crimmins DW, Baig W, et al. (2010) The MRI appearances of early vertebral osteomyelitis and discitis. Clin Radiol 65: 974-981.

11. Carragee EJ (1997) The clinical use of magnetic resonance imaging in pyogenic vertebral osteomyelitis. Spine (Phila Pa 1976) 22: 780-785

12. Alexiou E, Georgoulias P, Valotassiou V, Georgiou E, Fezoulidis I, et al. (2015) Multifocal septic osteomyelitis mimicking skeletal metastatic disease in a patient with prostate cancer. Hell J Nucl Med 18: 77-78.

13. Carragee EJ, Kim D, van der Vlugt T, Vittum D (1997) The clinical use of erythrocyte sedimentation rate in pyogenic vertebral osteomyelitis. Spine (Phila Pa 1976) 22: 2089-2093.

14. Gupta A, Kowalski TJ, Osmon DR, Enzler M, Steckelberg JM, et al. (2014) Long-term outcome of pyogenic vertebral osteomyelitis: a cohort study of 260 patients. Open Forum Infect Dis 1:ofu107.

15. Lozano-Calderon SA, Colman MW, Raskin KA, Hornicek FJ, Gebhardt M (2014) Use of bisphosphonates in orthopedic surgery: pearls and pitfalls. Orthop Clin north Am 45: 403-416.

16. Kordecki K, Lewszuk A, Puławska-Stalmach M, Michalak P, Łukasiewicz A, et al. (2015) Vertebroplasty of Cervical Vertebra. Pol J Radiol 80: 51-56.

17. Zapałowicz K, Radek M (2015) Percutaneous balloon kyphoplasty in the treatment of painful vertebral compression fractures: Effect on local kyphosis and one-year outcomes in pain and disability. Neurol Neurochir Pol 49: 11-15.

18. Roedel B, Clarençon F, Touraine S, Cormier E, Molet-Benhamou L, et al. (2014) Has the percutaneous vertebroplasty a role to prevent progression or local recurrence in spinal metastases of breast cancer? J Neuroradiol 42: 222-228.

19. Araujo JL, Veiga JC, Figueiredo EG, Barboza VR, Daniel JW, et al. (2013) Management of metastatic spinal column neoplasms--an update. Rev Col Bras Cir 40: 508-514.

20. Gasbarrini A, Boriani S, Capanna R, Casadei R, Di Martino A, et al. (2014) Management of the patient with metastasis to the vertebrae: Recommendations of the Italian Orthopaedic Surgery (SIOT) Bone Metastasis Group. Expert Rev Anticancer Ther 14: 143-150. 